\title{
Laparoscopic Right Radical Nephrectomy for Renal Cell Carcinoma with Cavatomy for Thrombus Extension in Renal Vein \& IVC
}

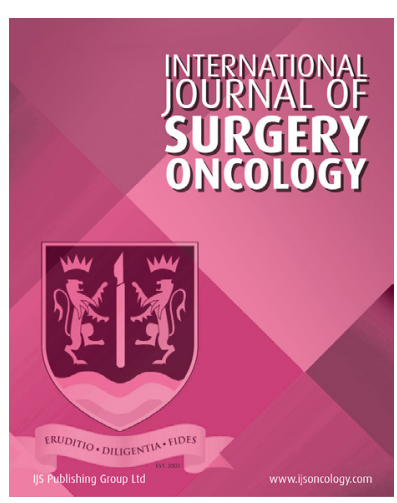

AJAY S. PUNPALE (1)

GANESH A. SWAMI

SAYALI S. SAMUDRE

*Author affiliations can be found in the back matter of this article

\begin{abstract}
Laparoscopic approach for management of renal cell carcinoma (RCC) has been increasingly use by many surgeons which can provide a better surgical option for T1T3aNOMO renal tumors. Surgical resection in the form of radical nephrectomy and caval thrombectomy represents the only option to obtain local control of the disease and is associated with durable oncologic control. Herein we present a case of 82 year old male presenting with haematuria and right flank pain with palpable mass in right lumbar region. CT scan revealed presence of right upper pole renal mass limited within Gerota's fascia with thrombus in right renal vein extending to IVC. Patient underwent laparoscopic right radical nephrectomy with cavatomy for thrombus extension. Procedure was uneventful and patient recovered well.
\end{abstract}

CORRESPONDING AUTHOR:

Dr. Sayali S. Samudre, M.B.B.S. M.S. 3rd year P.G. student

Chetanshilp apartment, flat no F-6, Sawarkar Nagar, N-5 CIDCO, Aurangabad. 431003. Maharashtra, IN

sayalisamudre@gmail.com

KEYWORDS:

Laparoscopic; nephrectomy; RCC; cavatomy

TO CITE THIS ARTICLE: Punpale AS, Swami GA, Samudre SS. Laparoscopic Right Radical Nephrectomy for Renal Cell Carcinoma with Cavatomy for Thrombus Extension in Renal Vein \& IVC. International Journal of Surgery: Oncology. 2021; 6(1), 25-32. DOI: https://doi. org/10.29337/ijsonco.123 


\section{SYNOPSIS}

We present a case of 82 year male patient diagnosed to have locally advanced right sided RCC (stage 3 ) who underwent laparoscopic radical nephrectomy with cavatomy for thrombus extension in renal vein and IVC.

\section{INTRODUCTION AND IMPORTANCE}

Laparoscopic radical nephrectomy with intact specimen extraction currently is an effective treatment option for T1-T3aNOMO renal cell carcinoma (RCC) and negative surgical margins evidence the technical efficacy of laparoscopy from an oncologic standpoint. It is currently the standard-of-care for patients with T1-3aNOMO renal tumors measuring $<$ or $=10-12 \mathrm{~cm}$ in size [1]. Laparoscopic transperitoneal radical nephrectomy can be a reliable option for RCC with level 1 and 2 thrombus in experienced centers [2]. An unusual hallmark of RCC is the biological predisposition for vascular invasion, with extension of tumor thrombus into the inferior vena cava (IVC) occurring in $10-25 \%$ of cases. If untreated there is poor prognosis and associated risks such as distal embolism and the sequelae of venous congestion. So the diagnosis of RCC with venous tumour thrombosis necessitates thorough evaluation, preoperative optimization and rapid coordination of a multidisciplinary team to prepare appropriately selected patients for surgical extirpation [3]. Herein, we present a case of 82 year old male presenting with haematuria and right flank pain with palpable mass in right lumbar region. Patient was diagnosed to have stage 3 Renal cell carcinoma (RCC).

The main objective of this article is to emphasize the importance of step wise approach in the surgical management of tumour thrombus in major blood vessels which is the crucial operative step in order to achieve complete resection of the tumour as well as to improve patient outcome.

This case report has been reported in line with the SCARE Criteria [17].

\section{CASE PRESENTATIONT}

A82 yr male patient presented with hematuria and right flank pain. Patient had no other associated co-morbidities, any significant past history and family history. On examination, there was a palpable lump in right lumbar region. All the lab investigations were done and were within normal limits. Contrast enhanced CT scan of thorax and abdomen revealed $7.8^{*} 7.9 \mathrm{~cm}$ right upper pole renal mass limited within Gerota's fascia with thrombus in right renal vein extending to IVC. No retroperitoneal lymph node enlargement seen (Figure 1). Patient was posted for Laparoscopic Right Radical Nephrectomy with cavatomy to remove thrombus and caval suturing.

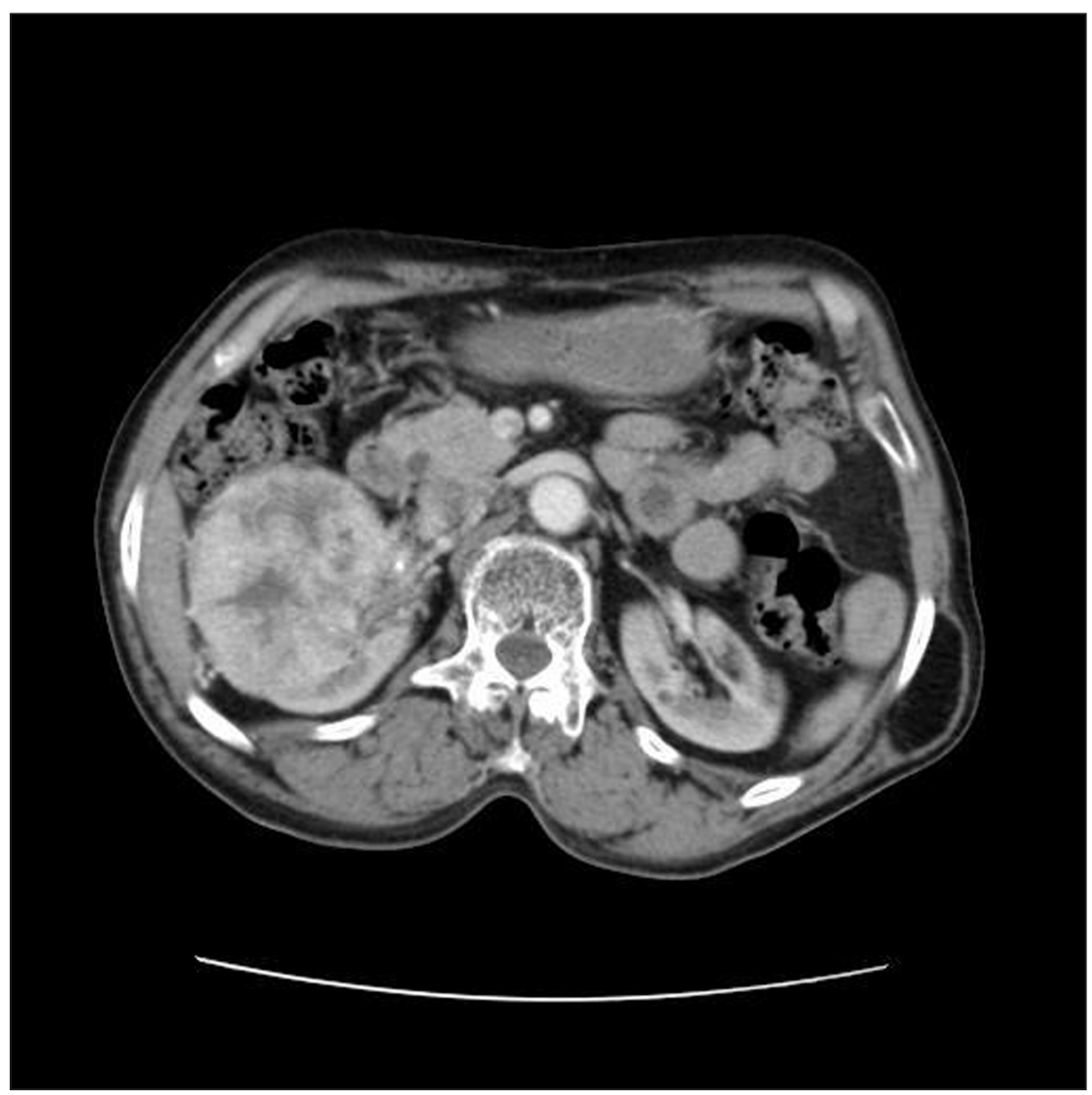

Figure 1 Axial section of CT scan showing renal mass with extension in IVC. 


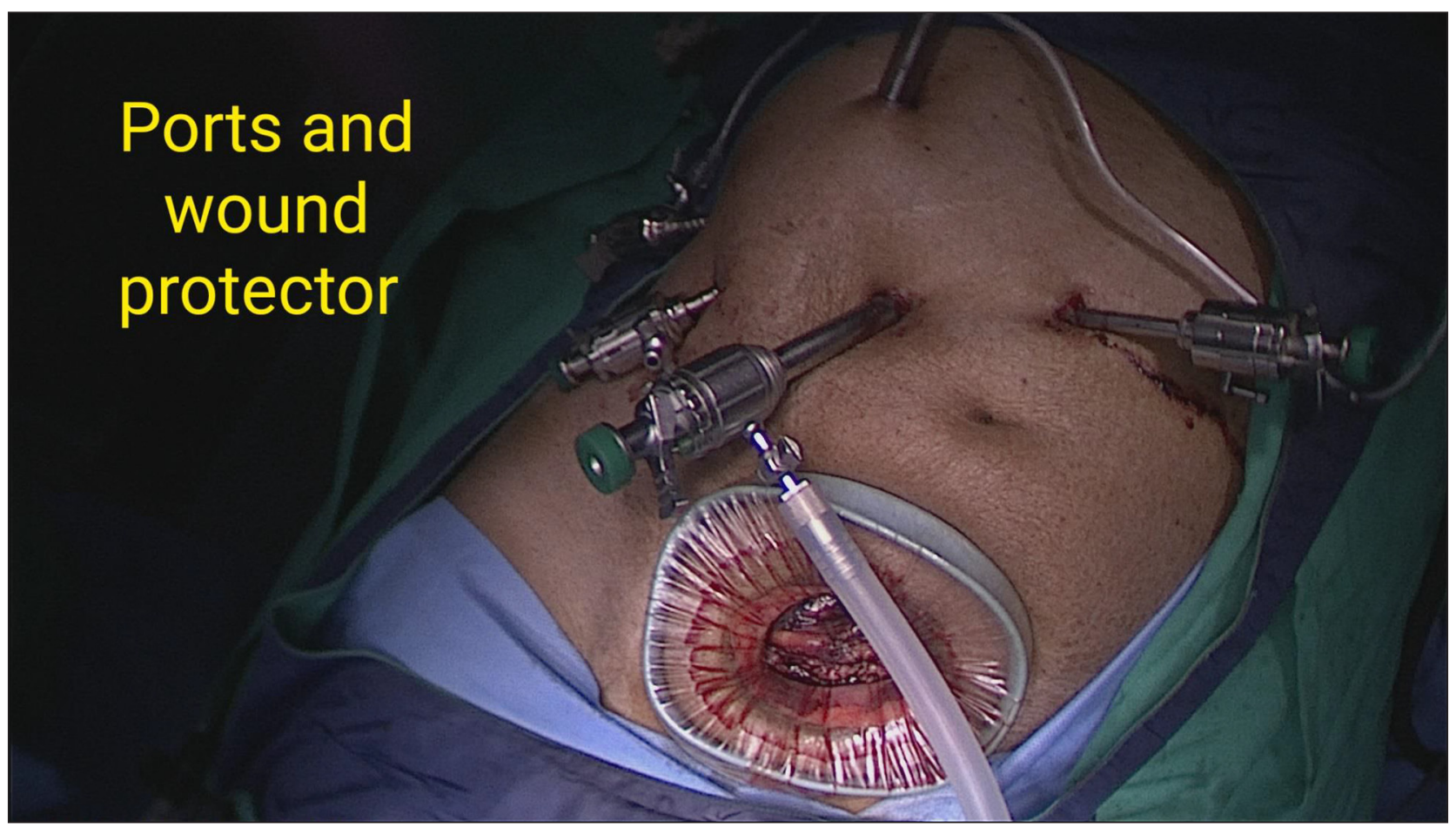

Figure 2 intraoperative photo showing site of ports and wound protector.

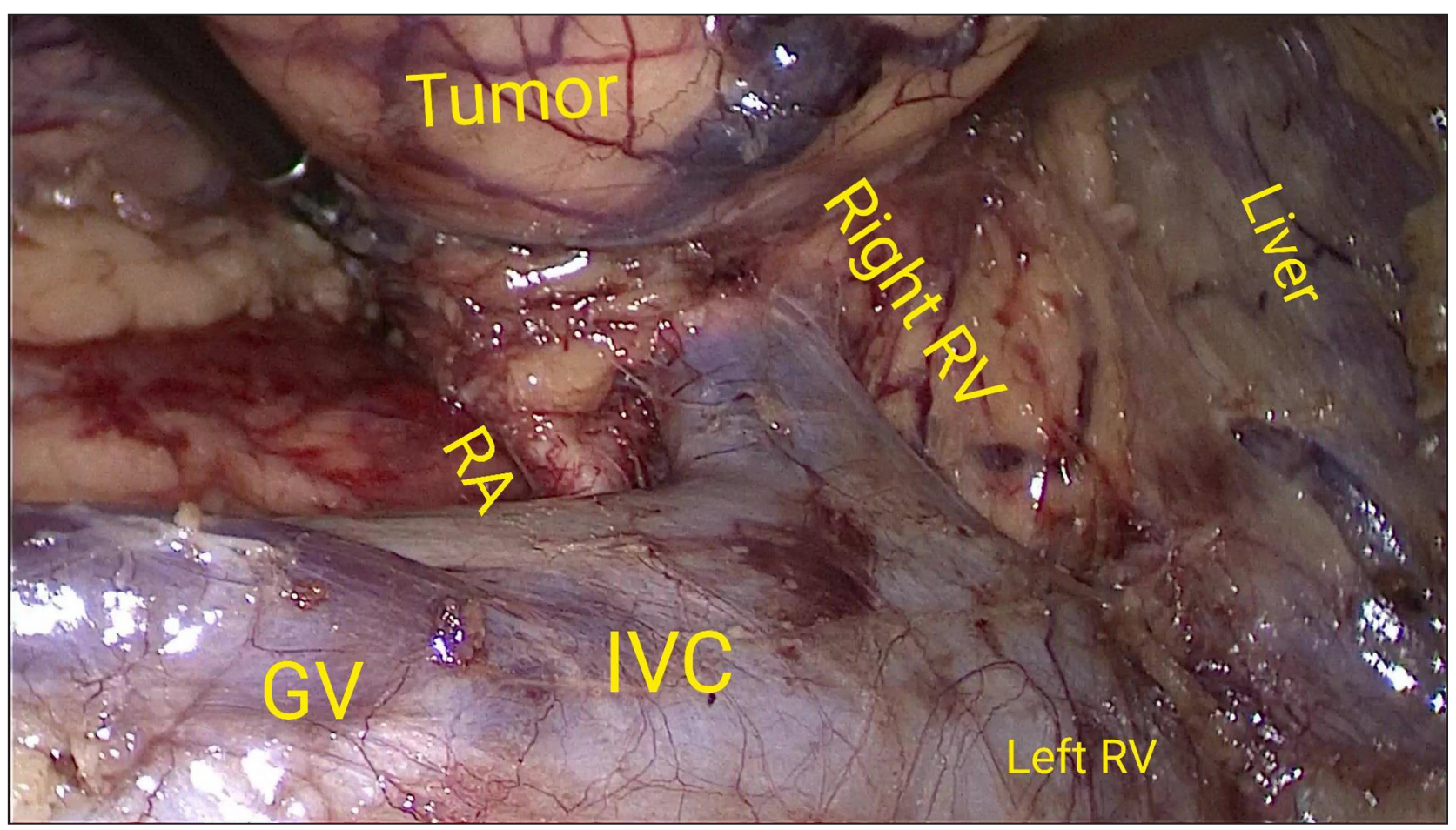

Figure 3 Intraoperative photo showing tumour and its relation to surrounding structures.

The procedure was performed at a specialised oncosurgery center.

General anesthesia was used. Patient was placed in semisupine position with right side up. To begin with 4 ports were inserted and $5^{\text {th }}$ port was added while caval suturing (Figure 2). Duodenal mobilization for IVC \& left RV exposure was done. Renal artery was clipped at origin in interaortocaval groove. Double vascular control obtained at supra and infrarenal IVC and left RV using vascular loop and laparoscopic bulldog. Suture was put inside before Cavotomy with suction kept ready (Figure 3). Cavatomy with removal of thrombus and suturing of IVC with 4-0 Proline completed (Figure 4). Clamps were released in sequence-Left RV, infrarenal and suprarenal. Further separation of kidney $\&$ specimen retrieval through wound protector was done successfully (Figures 5 and 6). Preaortic, para-aortic and interaortocaval lymph notes were dissected. Port sites closure was done. Total procedure 


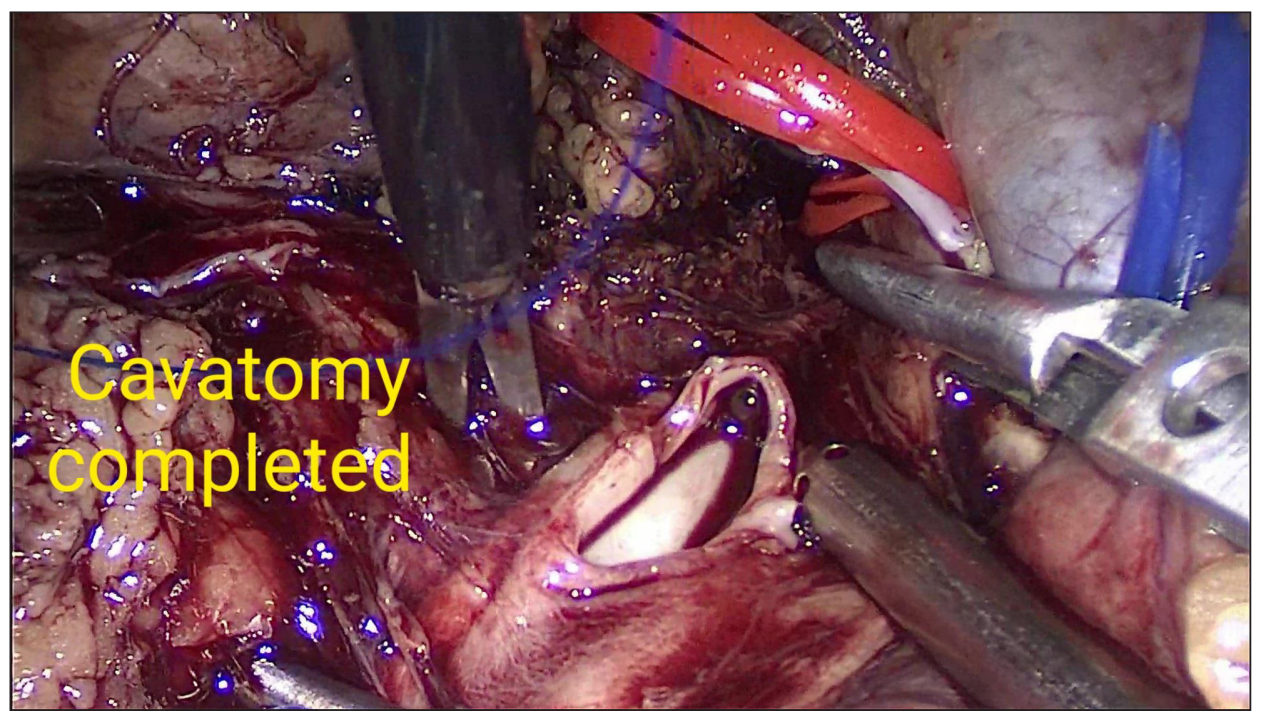

Figure 4 Intraoperative photo of cavatomy.

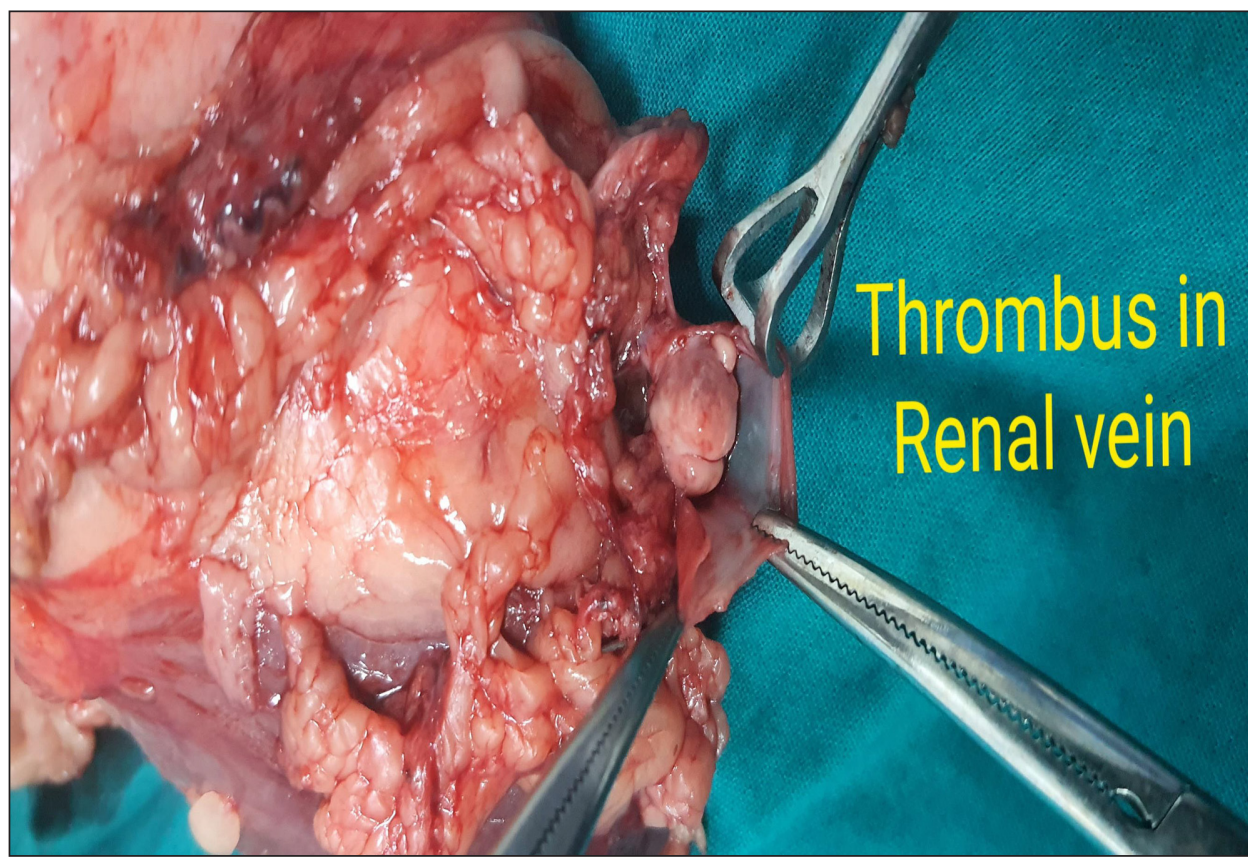

Figure 5 Specimen showing tumour thrombus in renal vein.

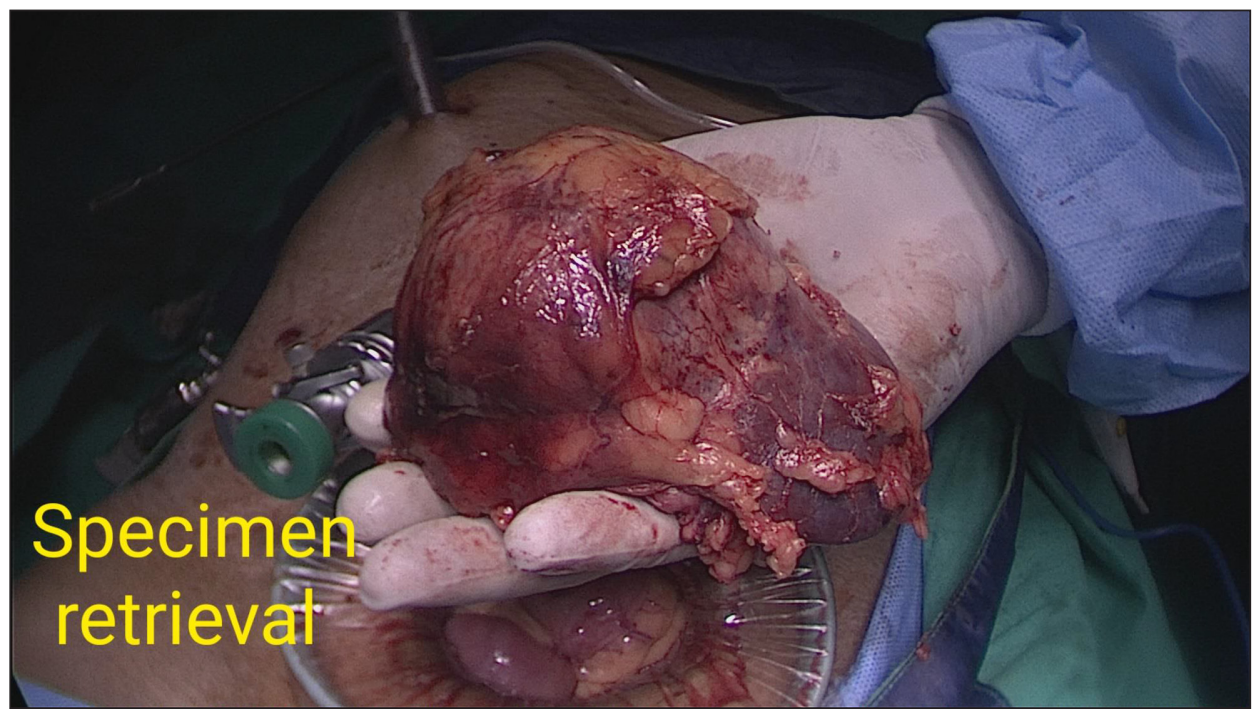

Figure 6 Specimen of tumour. 
time was $4 \mathrm{hr} 30$ min with blood loss of less than $50 \mathrm{~mL}$. No drain was kept. Postoperative course was uneventful and patient recovered well.

Patient was given adjuvant chemotherapy in the form ora doses ofl Sunitinib.

Histopathology report of the specimen revealed clear cell renal cell carcinoma (CCTCC) of right kidney. ISUP modified Fuhrman nuclear grade I. Tumor size $6.7 \times 6$ $\times 5.3 \mathrm{~cm}$. Tumor extension into renal vein. Renal pelvis and sinus, Renal capsule and Gerota fascia, Adrenal gland,all hilar margins, 2 hilar nodes free of tumour cells. TUMOR STAGE - pT3NO (AJCC 8th ed).

\section{CLINICAL DISCUSSION}

In the past years, renal cell carcinoma (RCC) has been studied all over the world. RCC is a highly vascular malignancy with a tendency to invade the venous system and create a tumor thrombus either in the renal vein or the inferior vena cava (IVC). Around $4 \%$ to $10 \%$ of RCCs have a tumor thrombus in the venous circulation, specifically the renal vein and IVC [4].

The importance of preoperative imaging for surgical planning is of utmost importance. Tumor thrombus extending to the level of the hepatic veins or higher may require cardiopulmonary bypass and circulatory arrest to provide insurance against excessive blood loss. Patients slated for cardiopulmonary bypass and circulatory arrest should have cardiac evaluation which includes stress testing or a coronary angiogram. If significant coronary artery disease is discovered, it may be treated with either a stent or bypass grafting [5].

Operative therapy of non-metastatic RCC has evolved from radical nephrectomy to less radical techniques that spare the adrenal gland as well as nephron-sparing surgery. Laparoscopic or robot-assisted approaches are commonly used. Even less invasive techniques like cryoablation, radiofrequency ablation or active surveillance are applied for small renal masses, when indicated. Recently cytokine therapy was the standard of care for metastatic RCC. Successful use of tyrosine kinase inhibitors, mTOR inhibitors, and anti-VEGF antibodies have been introduced. The development of checkpoint inhibitors has changed the systemic treatment of RCC [6].

Surgical resection of RCC is the benchmark for longterm cure. Open or laparoscopic radical nephrectomy is considered the gold standard for stage T1b-T4 tumors but nephron-sparing surgery is the preferred operative modality for small renal masses demonstrating equivalent oncologic efficacy and improved renal function outcomes compared with complete nephrectomy and it can safely be conducted laparoscopically with or without robotic assistance. RCC with intravenous tumor thrombus are surgically challenging but multidisciplinary surgical approaches can provide long-term benefit for these patients. The role of cytoreductive nephrectomy and metastasectomy in patients with metastatic RCC (mRCC) may be beneficial for patients in the era of targeted therapy [7].

As life expectancy continues to increase, the management of RCC in elderly patients can be challenging. Laparoscopic approach can be better than open approach in elderly patients due to decrease post operative morbidity [8]. Since the introduction of the laparoscopic nephrectomy (LN) procedure by Clayman et al in 1991, the role of laparoscopy in the urology field has continued to evolve. LN involves a myriad of procedures including simple, donor and radical nephrectomy. Counseling all patients considering a laparoscopic approach to their renal pathology is important [9]. The laparoscopic approach to radical nephrectomy has been associated with improved patient outcomes including decreased post operative pain, shorter hospital stay, rapid recovery and improved aesthetic cosmetic appearance. It may be performed in three different types of surgical procedures including laparoscopic hand-assisted radical nephrectomy, transperitoneal radical nephrectomy, and retroperitoneal radical nephrectomy [10].

Using the modified Pfannenstiel incision in laparoscopic radical nephrectomy for specimen retrieval offers the benefits of a low abdominal incision and improved cosmesis over the traditional muscle-cutting extension of an upper abdominal, lateral port siteand can be considered a potential alternative for traditional laparoscopic nephrectomy [11].

Laparoscopic nephrectomy by the retroperitoneal approach is increasingly being employed as the technique of choice at many centers for removal of a kidney indicated for symptomatic end-stage renal disease of benign etiology. In selected patients with T1-T3aNOMO renal tumors $<8 \mathrm{~cm}$, retroperitoneal laparoscopic radical nephrectomy may be a viable treatment option [12].

For surgeons attempting minimally invasive IVC tumor thrombectomy, it is of paramount importance to obtain complete caval isolation, with circumferential control of the infrarenal and suprarenal IVC, the contralateral renal vein and lumbar veins. Early ligation of the renal artery which reduces blood flow through venous collaterals and potentially limits blood loss later [14]. Additionally if there are any accessory renal arteries, they should be ligated. For right sided tumors, approaching renal artery in the interaortocaval space decreases early manipulation of the IVC and right renal vein [13]. Then, the vena caval thrombectomy is performed. The level of tumor thrombus guides the approach to tumor thrombectomy (Tables 1 


\begin{tabular}{lll}
\hline PREOPERATIVE CLASSIFICATION & DEFINITION & SURGICAL APPROACH \\
\hline A & $\begin{array}{l}\text { IVC without venous occlusion, noassociated } \\
\text { distal or bland thrombus }\end{array}$ & Primary cavorrhaphy \\
\hline B & $\begin{array}{l}\text { IVC partially occluded with distalbland } \\
\text { thrombus in the pelvis only }\end{array}$ & $\begin{array}{l}\text { Intraoperative deployment of } \\
\text { Greenfield (IVC) filter }\end{array}$ \\
\hline C & Partial IVC occlusion by tumorthrombus with & $\begin{array}{l}\text { Staple/ligate the IVC inferior to thenlevel of the IVC } \\
\text { tumor thrombus withpermanent interruption of } \\
\text { the IVC }\end{array}$ \\
\hline D & $\begin{array}{l}\text { Total occlusion of the IVC by } \\
\text { tumorthrombus/bland thrombus }\end{array}$ & $\begin{array}{l}\text { Segmental resection of the IVC with permanent } \\
\text { interruption of the IVC }\end{array}$ \\
\hline IVC, inferior vena cava. & &
\end{tabular}

Table 1 Preoperative classification of bland thrombus and degree of venous occlusion and proposed surgical management [13].

\begin{tabular}{ll}
\hline $\begin{array}{l}\text { TUMOR } \\
\text { THROMBUS LEVEL }\end{array}$ & DEFINITION \\
\hline 0 & Tumor thrombus is limited to the renal vein, detected clinically or during assessment of the pathological specimen \\
\hline I & Tumor thrombus extends into the IVC, $<2 \mathrm{~cm}$ above the renalvein \\
\hline II & Tumor thrombus extends into the IVC, $>2 \mathrm{~cm}$ above the renalvein but below the hepatic veins \\
\hline III & Tumor thrombus extends above the hepatic veins but below thediaphragm \\
\hline IV & Tumor thrombus extends above the diaphragm, including atrialthrombus \\
\hline
\end{tabular}

Table 2 Classification of tumor thrombus level [3].

and 2). The ostium of the renal vein is then sharply circumscribed which permits the removal of the tumor thrombus en bloc with the nephrectomy specimen and attached renal vein. Once the IVC is circumferentially mobilized via ligation and division of the lumbar veins, vascular clamps are placed sequentially, first the suprarenal IVC proximal to thrombus, then on the contralateral renal vein and lastly on the infrarenal IVC. A test clamp should be performed, as the IVC is cross clamped initially to ensure that patient remains hemodynamically stable during this procedure. Once vascular control is achieved, an 'L'-shaped cavatomy is performed longitudinally along the isolated IVC [13]. The thrombus is dissected from and the ostium of the renal vein is circumferentially excised, permitting the thrombus to be removed in continuity with the kidney. The lumen of the IVC is inspected for residual tumor thrombus, flushed and closed in a running manner with a continuous 4-0 polypropylene suture after ensuring that all thrombus and air is aspirated from the IVC lumen before completion of the cavorrhaphy. For cavorrhaphy, patient is placed in Tredelenburg position and infrarenal clamps released to allow back-bleeding prior to completing the cavorraphy. The contralateral renal vein and suprarenal IVC clamps are sequentially released after cavorrhaphy.

Assessment of the need for more extensive resection of the IVC wall with or without complex reconstruction should be done. Invasion of the IVC wall by tumor thrombus increases the risk for recurrence and poor prognosis [15].
Followingradical nephrectomy, regional retroperitoneal lymphadenectomy may be performed [16].

\section{CONCLUSION}

Laparoscopic radical nephrectomywith cavatomy can provide standard care for patients with renal cell carcinomawith tumour thrombus in renal veil extending to inferior vena cava in experienced hands.

\section{ETHICS AND CONSENT}

Written informed consent was obtained from the patient for publication of this case report and accompanying images. A copy of the written consent is available for review by the Editor-in-Chief of this journal on request.

\section{COMPETING INTERESTS}

The authors have no competing interests to declare.

\section{AUTHOR CONTRIBUTION}

Dr Ajay S. Punpale main operating surgeon. Dr Ganesh A. Swami 1st assistant surgeon. Dr. Sayali S. Samudre observer, post graduate student research registration. 
AUTHOR AFFILIATIONS

Ajay S. Punpale, M.B.B.S., M.S., DNB, MNAMS, FCPS ID orcid.org/ 0000-0002-9275-9094

Consultant onco-surgeon, Latur superspeciality hospital, Nanded road, Latur, 413512, Maharashtra, IN

\section{Ganesh A. Swami, M.B.B.S., M.S.}

Department of general surgery, VDGIMS Latur, 413512, Maharashtra, IN

Sayali S. Samudre, M.B.B.S. M.S. $3^{\text {rd }}$ year P.G. student Department of general surgery, VDGIMS Latur, 413512 , Maharashtra, IN

\section{REFERENCES}

1. Gill IS, Meraney AM, Schweizer DK, Savage SS, Hobart MG, Sung GT, Nelson D, Novick AC. Laparoscopic radical nephrectomy in 100 patients: a single center experience from the United States. Cancer. 2001 Oct 1; 92(7): 1843-55. DOI: https://doi.org/10.1002/10970142(20011001)92:7<1843::AID-CNCR1701>3.0.CO;2-W

2. Cinar O, Gunseren KO, Cicek C, Vuruskan BA, Vuruskan H. Laparoscopic Transperitoneal Radical Nephrectomy for Renal Masses with Level I and II Thrombus. J Laparoendosc Adv Surg Tech A. 2019 Jan; 29(1): 35-39.

3. Psutka SP, Leibovich BC. Ther Adv Urol 2015; 7(4): 216229. DOI: https://doi.org/10.1177/1756287215576443

4. Marshall F, Dietrick D, Baumgartner W, et al. Surgicalmanagement of renal cell carcinoma with intracavalneoplastic extension above the hepatic veins. J Urol. 1988; 139(6): 1166-72. DOI: https://doi.org/10.1016/ S0022-5347(17)42848-5

5. Belis J, Pae W, Rohner T, et al. Cardiovascular evaluationbefore circulatory arrest for removal of venacava extension of renal carcinoma. J Urol. 1989; 141(6): 1302-7. DOI: https://doi.org/10.1016/S0022-5347(17)41288-2

6. Doehn C. 50 JahreNierenzellkarzinom [50 years of renal cell carcinoma]. Aktuelle Urol. 2019 Aug; 50(4): 378-385. German. DOI: https://doi.org/10.1055/a-0966-8380

7. Krabbe LM, Bagrodia A, Margulis V, Wood CG. Surgical management of renal cell carcinoma. Semin Intervent Radiol. 2014 Mar; 31(1): 27-32. DOI: https://doi. org/10.1055/s-0033-1363840
8. Lai FC, Kau EL, Ng CS, Fuchs GJ. Laparoscopic nephrectomy outcomes of elderly patients in the 21st century. J Endourol. 2007 Nov; 21(11): 1309-13. DOI: https://doi. org/10.1089/end.2007.9885

9. Pareek G. Laparoscopic nephrectomy. Minerva Urol Nefrol. 2008 Dec; 60(4): 273-9.

10. Galli B, Munver R, Sawczuk I, Kochis E. Laparoscopic radical nephrectomy in renal cell carcinoma. Urol Nurs. 2005 Apr; 25(2): 83-6, 133; quiz 87.

11. Zhang SD, Ma LL, Huang Y, Zhang HX, Liu K, Qiu M. [Transabdominal laparoscopic radical nephrectomy of modified Pfannenstiel incision]. Beijing Da Xue Xue Bao Yi Xue Ban. 2014 Aug 18; 46(4): 638-41.

12. Gill IS. Retroperitoneal laparoscopic nephrectomy. Urol Clin North Am. 1998 May; 25(2): 343-60. DOI: https://doi. org/10.1016/S0094-0143(05)70023-9

13. Blute M, Leibovich B, Lohse C, Cheville J and Zincke H. The Mayo Clinic experience withsurgical management, complications and outcome forpatients with renal cell carcinoma and venous tumourthrombus. BJU Int. 2004; 94: 33-41. DOI: https://doi.org/10.1111/j.1464410X.2004.04897.x

14. Ciancio G, Vaidya A and Soloway M. Early ligation of the renal artery using the posterior approach: a basic surgical concept reinforced during resection of large hypervascular renal cell carcinoma with or without inferior vena cava thrombus. BJU Int. 2003; 92: 488-489. DOI: https://doi. org/10.1046/j.1464-410X.2003.04372.x

15. Hirono M, Kobayashi M, Tsushima T, Obara W, Shinohara $\mathbf{N}$, Ito $\mathbf{K}$, et al. Impacts of clinicopathologic and operative factors on shortterm and long-term survival in renal cell carcinoma with venous tumor thrombus extension: a multiinstitutional retrospective study in japan. BMC Cancer. 2013; 13: 447. DOI: https://doi.org/10.1186/1471-240713-447

16. Whitson J, Harris C, Reese A and Meng M. Lymphadenectomy improves survival of patients with renal cell carcinoma and nodal metastases. J Urol. 2011; 185: 16151620. DOI: https://doi.org/10.1016/j.juro.2010.12.053

17. Agha RA, Franchi T, Sohrabi C, Mathew G, for the SCARE Group. The SCARE 2020 Guideline: Updating Consensus Surgical CAse REport (SCARE) Guidelines. International Journal of Surgery. 2020; 84: 226-230. 
TO CITE THIS ARTICLE:

Punpale AS, Swami GA, Samudre SS. Laparoscopic Right Radical Nephrectomy for Renal Cell Carcinoma with Cavatomy for Thrombus Extension in Renal Vein \& IVC. International Journal of Surgery: Oncology. 2021; 6(1), 25-32. DOI: https://doi.org/10.29337/ijsonco.123

Submitted: 19 April 2021 Accepted: 26 May 2021 Published: 16 June 2021

COPYRIGHT:

(c) 2021 The Author(s). This is an open-access article distributed under the terms of the Creative Commons Attribution 4.0 International License (CC-BY 4.0), which permits unrestricted use, distribution, and reproduction in any medium, provided the original author and source are credited. See http://creativecommons.org/licenses/by/4.0/.

International Journal of Surgery: Oncology is a peer-reviewed open access journal published by IJS Publishing Group. 